\title{
IMPLEMENTASI MEDIA PEMBELAJARAN VLOG MATERI DAKWAH PADA MAHASISWA BERDASARKAN ASPEK KETERAMPILAN BERBAHASA
}

\author{
Dedi Romli Triputra ${ }^{1}$, Prasetyo Yuli Kurniawan*2 \\ ${ }^{1}$ Prodi Pendidikan Guru Sekolah Dasar, Fakultas Keguruan dan Ilmu Pendidikan, \\ Universitas Muhadi Setiabudi Brebes, Indonesia \\ ${ }^{2 *}$ Prodi Pendidikan Bahasa dan Sastra Indonesia, Fakultas Keguruan dan Ilmu \\ Pendidikan, Universitas Muhadi Setiabudi Brebes, Indonesia \\ e-mail: *prasetyoyulikurniawan@gmail.com
}

\begin{abstract}
ABSTRAK
Media pembelajaran pada era revolusi industri 4.0 dituntut untuk berorientasi pada IT. Dosen harus menyadari bahwa penggunaan media pada era sekarang mempengaruhi pencapaian pembelajaran. Salah satu media pembelajaran yang dapat digunakan yaitu media vlog. Media vlog dipilih karena dapat menjadikan mahasiswa lebih aktif dan kreatif dalam penggunaannya. Terlebih dalam materi dakwah, mahasiswa mampu memanfaatkan sebuah handphone dimanapun berada sesuai dengan topik yang akan dibicarakan atau realitas yang ada. Sehingga dalam materi dakwah sangat tepat digunakan media vlog sebagai media pembelajaran. Tujuan penelitian ini yaitu untuk memaparkan hasil pembelajaran menggunakan media vlog pada materi dakwah serta menguji keefektifan media vlog dalam materi dakwah berdasarkan aspek keterampilan berbahasa. Metode yang digunakan yaitu metode ekseprimen dengan desain postest only control group design. Hasil penelitian ini yaitu bahwa nilai rata-rata mahasiswa dalam materi dakwah dilhat dari aspek keterampilan berbahasa yaitu mendapatkan nilai 83. Sedangkan pada kelas kontrol mendapatkan nilai rata-rata 78. Kemudian berdasarkan uji T bahwa media vlog dinyatakan efektif digunakan dalam materi dakwah. Oleh karena itu, media vlog sangat penting digunakan khususnya dalam materi dakwah karena sudah terbukti efektif.
\end{abstract}

Kata kunci: eksperimen, media pembelajaran, media vlog, keterampilan berbahasa

\begin{abstract}
The Media learning in the era of the 4.0 industrial Revolution is demanded to be oriented for IT. Lecturers should realize that the use of media in the present era affects the achievement of learning. One of the learning media that can be used is vlog. Vlog Media is chosen because it can make students more active and creative. In terms of da'wah material, students are able to utilize a mobile phone anywhere in accordance with the topic to be discussed or the reality that is. So in Da'wah material very precise use of media vlog as a learning medium. The purpose of this research is to present learning outcomes using vlog Media on Da'wah material and to test the effectiveness of vlog media in Da'wah materials based on the language skills aspect. Method used is expepriment method with design postest only control group design. The result of this research is that the average value of students in the material is seen from the language skills aspect, namely the value of 83. While in the control class get an average value of 78. Then based on T-test that the media vlog is stated effectively used in da'wah material. Therefore, vlog media is very important to use especially in da'wah material because it has been proven effective.
\end{abstract}

Keywords: Experiments, learning Media, vlog media, a language 
Jurnal KONTEKSTUAL, Volume 1, No. 01, Agustus 20XX, pp. 18-25

\section{PENDAHULUAN}

Aktivitas dakwah merupakan hal yang sangat mendasar dalam Islam. Sebab tanpa adanya dakwah, maka ajaran Islam tidak bisa sampai apalagi dipahami oleh umat manusia. Selain itu, agama Islam juga selalu mendorong umatnya agar berperiaku baik sekaligus mengajak orang lain agar menjadi pribadi yang baik, memiliki akhlak dan berpengetahuan.[1]

Pada era revousi industri 4.0 ini, teknologi informasi dan komunikasi berkembang semakin pesat dan menuntut semua pihak untuk turut serta beradaptasi mengembangkan diri serta mengikuti arus memanfaatkan hasil tekhnologi dalam segala aktifitas baik individu maupun sosial. Dampak perkembangan teknologi ini berimbas pula pada proses aktivitas dakwah dimana para da'i harus mampu melakukan berbagai inovasi dan kreatifitas agar proses dakwah selalu relevan dan diterima sesuai dengan perkembangan zaman.[2]

Pada masa kini, sangat jamak ditemukan anak-anak usia remaja memiliki kecenderungan dalam mencari segala sumber pengetahuan tidak terkecuali pengetahuan agama melalui internet. salah satu media pencari pengetahuan tersebut adalah melalui chanel youtube. Meski sampai saat ini kecenderungan yang dapat ditemui bahwa umumnya mereka hanya memanfaatkan internet sebagai sarana hiburan semata. namun seorang juru dakwah semestinya mampu mengolah kreativitasnya dalam berdakwah melalui sajian-sajian yang menarik di internet agar konten-konten dakwah semakin digemari. Pada prinsipnya dakwah adalah aktivitas mengubah objek dakwah agar mengikuti dan menjalankan ajaran Islam. Ajakan ini bisa dilakukan dengan cara mendekati sasaran sesuai dengan karakteristik mereka dan kecenderungan mereka. Hal yang menarik didalam sajian dakwah bisa dilakukan jika bisa menyajikan bahasa yang komunikatif, mudah difahami, dan sesuai dengan realitas masa kini. [3]
Pada pembelajaran matakuliah PAI materi dakwah di kampus universias Muhadi Setiabudi, mahasiswa dituntut mampu memanfaatkan media online berupa vlog untuk menuangkan kreatifitasnya di dalam berdakwah pada kalangan milenial. Tentu dakwah dalam kerangka yang lebih sempit yaitu ajakan kepada kebaikan, bukan dakwah dalam pengertian penyajian atau membuat fatwa-fatwa agama yang pastinya bukan kapasitas mereka sebagai mahasiswa jurusan non agama.

Didalam materi dakwah yang disampaikan atau diungkapkan oleh mahasiswa, selain daripada konten dakwah tersebut, penilaian tugas akan ditinjau pula dari sisi retorika atau kemampuan berbicara didalam penyampaian dakwah yang mereka rekam dalam bentuk vlog.

\section{KAJIAN TEORI}

Ajaran Islam secara substasi berisi tiga hal utama yaitu Iman atau keyakinan, Islam sebagai perwujudan pelaksanaan ibadah dan yang ketiga Ikhsan sebagai perwujudan etika atau adab untuk menjadi manusia yang sempurna (insan kamil). Ketiga hal tersebut bersumber pada sumber hukum Islam berupa al-Qur'an dan sunnah Rasul saw. Ajaran Islam tersebut tentu harus disampaikan kepada umat melalui jalan dakwah. Keberhasilan di dalam berdakwah bergantung kepada manejemen dakwah agar pesan-pesan dakwah sampai dan diterima oleh objek dakwah. Diantara beberapa penunjang keberhasilan dakwah adalah media (washilah) dakwah dan konten dari sisi penyampaian atau ketrampilan berbahasa. Media dakwah yang sesuai di kalangan milenial saat ini adalah berdakwah melalui vlog yang singkat namun kaya akan substansi.

\section{Dakwah Islam}

Dakwah merupakan proses mengajak, menyeru, dan membimbing kepada umat manusia untuk berbuat baik dengan mengikuti arahan Allah dan rasulNya. Usaha tersebut dilakukan agar mereka 
Jurnal KONTEKSTUAL, Volume 1, No. 01, Agustus 20XX, pp. 18-25

mengetahui,mengimani serta mengamalkan ajaran Islam pada semua aspek kehidupan. Dakwah diupayakan dengan cara yang bijaksana, agar tercapai kehidupan yang sejahtera di dunia dan di akhirat. [1]

Dakwah kepada umat bisa disampaikan melalui berbagai media dan cara. pada umumnya, media dakwah yang banyak digunakan adalah ta'lim atau pengajian-pengajian yang secara langsung antara juru dakwah dan sasaran dakwah bertatap muka dalam satu tempat. objek dakwah bisa mendapatkan pemahaman dari sumbernya secara langsung. Dakwah semacam ini bersifat normatif dan lebih banyak terfokus pada ceramah, saran dakwahnya hanya menyentuh kalangan masyarakat tertentu, diskursus halal haram, baik dan buruk, dosa dan pahala, surga dan neraka, dan sebagainya. Potret dakwah yang demikian, menjadikan dakwah menjadi tidak populer dan cenderung membuat masyarakat jenuh atau bosan. [4]

Perkembangan teknologi dan sistem informasi dewasa ini sesungguhnya merupakan suatu potensi yang besar manfaatnya untuk dapat digunakan daam kepentingan dakwah Islam. Di satu sisi memang media dapat mempermudah dalam menyampaikan pesan atau informasi, dan di lain pihak, kehadiran media memberikan dampak yang lebih besar bagi kehidupan masyarakat pada skala yang lebih luas. Dengan kata lain Perkembangan teknologi dan sistem informasi sangat bermanfaat bagi dunia Muslim, karena para dai atau juru dakwah mampu menjadwal belajar, mengaji, dan menonton hal-hal yang bernilai dakwah.[5]

\section{Media vlog}

Vlog atau video blog merupakan rekaman video singkat berisi mengenai opini, cerita atau kegiatan harian yang biasanya dibuat tertulis pada blog. Vlog pada mulanya merupakan sarana untuk mengekspresikan diri dan pendapat kepada publik. Vlog pada awal kemunculannya tidak bisa dikaterogikan dalam konten yang bersifat memberi pendidikan melainkan lebih kepada pemberian informasi baik yang bersifat umum seperti tempat-tempat baru atau tren model busana baru atau bisa juga berisi informasi bersifat pribadi karena Vlog biasa ditampilkan dalam bentuk video yang berisi tentang Kegiatan keseharian, Pendapat mengenai suatuhal, ataupun Curahan hati seseorang mengenai sesuatu.[6]

Pada abad 21 terjadi Pergeseran paradigma pembelajaran dalam dunia pendidikan yaitu dari teacher centered bergeser menjadi student active learning. salah satu alternatif untuk mengurangi pembelajaran teacher centered, pendidik tidak hanya mengandalkan buku pegangan mengajar, tetapi harus dilengkapi dengan model pembelajaran yang tepat salah satunya Media vlog yang mempunyai kelebihan yaitu peserta didik terlibat aktif didalamnya. peserta didik dapat kreatif dalam membuat vlog, dan proses belajar mengajar menjadi menyenangkan. [7]

\section{Keterampilan berbahasa}

Keterampilan berbicara merupakan salah satu ketrampilan yang harus dikembangkan untuk mencapai tujuan pembelajaran. Berbicara merupakan kemampuan mengucapkan bunyi-bunyi artikulasi atau kata-kata yang mengekspresikan, menyatakan, serta menyampaikan pikiran, gagasan, dan perasaan. Melalui berbicara, seseorang dapat menyampaikan informasi kepada orang lain melaui ujarannya. ketrampilan berbicara merupakan kegiatan komunikasi dua arah yang berkaitan erat dengan menyimak. Dalam berkomunikasi, seseorang tidak akan berbicara jika tidak terdapat lawan bicara yag akan menyimak, begitu juga sebaliknya seseorang tidak mungkin menyimak jika tidak ada orang lain yang berbicara. [8]

\section{METODE PENELITIAN}

\section{Jenis Penelitian}


Jurnal KONTEKSTUAL, Volume 1, No. 01, Agustus 20XX, pp. 18-25

Penelitian eksperimen merupakan metode penelitian yang digunakan untuk mencari pengaruh perlakuan tertentu terhadap yang lain dalam kondisi yang dikendalikan (Sugiyono, 2012:109). Eksperimen pada penelitian ini menggunakan jenis pre-experiment dengan desain One-shoot Pretest-Posttest.

\section{Waktu dan Tempat Penelitian}

Pelaksanaan penelitian ini terletak di Universitas Muhadi Setibudi Brebes. Sedangkan untuk waktu penelitian ini dilaksanakan pada bulan februari dan maret tahun 2019.

\section{Target/ Subjek Penelitian}

Subjek penelitian yaitu berupa orang, tempat, atau benda yang menjadi sasaran untuk penelitian. Subjek dalam penelitian ini yaitu mahasiswa pendidikan guru sekolah dasar Universitas Muhadi Setiabudi Brebes.

\section{Prosedur}

Penelitian eksperimen terdapat langkah-langkah yang perlu dilakukan. Langkah-langkah pada penelitian ini yaitu sebagai berikut.

a. Memilih dan merumuskan masalah

b. Merumuskan hipotesis

c. Memilih desain penelitian eksperimen

d. Melaksanakan eksperimen

e. Mengumpulkan data

f. Mengolah data

g. Perumusan kesimpulan

\section{Data, Instrument, dan Teknik Pengumpulan Data}

Data merupakan fakta empirik yang dikumpulkan oleh peneliti sebagai pemecah masalah dalam penelitian. Data pada penelitian ini yaitu data nilai awal (pretest) dan data nilai akhir (posttest) mahasiswa pada materi dakwah.

Instrumen penelitian yang digunakan terdapat beberapa macam. Instrumen dalam penelitian ini yaitu sebagai berikut.

1. Tes
Tes digunakan untuk mengetahui kemampuan mahasiswa dalam materi dakwah. Tes ini digunakan pada awal atau sebelum diberi perlakuan dan pada akhir setelah diberi perlakuan.

\section{Angket}

Angket pada penelitian ini digunakan untuk mendapat tanggapan dari mahasiswa tentang media vlog yang telah diberikan. Hal tersebut bertujuan sebagai tolok ukur tercapainya media vlog bagi mahasiswa.

3. Dokumentasi

Dokumentasi digunakan sebagai pencatatan peristiwa penelitian. Dokumentasi pada penelitian ini berupa gambar-gambar pada saat penelitian ini berlangsung dari awal sampai akhir.

Teknik pengumpulan data yang digunakan dalam pada penelitian ini yaitu sebagai berikut.

\section{a. Pretest (tes awal)}

Pada teknik pengumpulan data ini, mahasiswa pendidikan guru sekolah dasar diberikan tugas untuk praktik dakwah. Hal tersebut bertujuan untuk mengetahui kemampuan awal mahasiswa sebelum diberikan perlakuan (treatment) dengan menggunakan media vlog.

b. Memberikan perlakuan (treatment)

Perlakuan (treatment) pada penelitian ini dilakukan setelah mahasiswa menyelesaikan pretestnya. Pada teknik pengumpulan data ini, materi dakwah diberikan dengan menggunakan media vlog sebagai bentuk perlakuan kepada mahasiswa.

c. Memberikan posttest

Pada tahap pengumpulan data ini, mahasiswa diberikan tes akhir untuk mengetahui perbandingan kemampuan mahasiswa sebelum digunakan media vlog dan sesudah menggunakan media vlog.

d. Memberikan Angket

Angket diberikan setelah dilakukan tes akhir (posttest). Angket tersebut digunakan untuk mengetahui tanggapan mahasiswa media vlog dalam materi dakwah. 
Jurnal KONTEKSTUAL, Volume 1, No. 01, Agustus 20XX, pp. 18-25

\section{HASIL DAN PEMBAHASAN}

Hasil penelitian terdiri atas dua aspek yaitu data nilai mahasiswa materi dakwah dan keefektifan media vlog dalam materi dakwah. Untuk lebih lengkapnya dapat dijelaskan sebagai berikut.

\section{a. Data Nilai Mahasiswa Materi Dakwah}

Data nilai mahasiswa terdiri atas data nilai awal (pretest) dan nilai akhir (posttest). Pada data nilai awal diperoleh dari tes yang diberikan kepada mahasiswa sebelum diberi perlakuan menggunakan media vlog. Nilai materi dakwah berdasarkan aspek kebahasaan (keterampilan berbicara) pada tes awal (pretes) kelas eksperimen mahasiswa Pendidikan Guru Sekolah Dasar Universitas Muhadi Setiabudi berbentuk data nilai awal mahasiswa. Adapun nilai tersebut dapat dilihat pada Tabel 1 berikut ini.

Tabel 1. Nilai Awal (pretest) Kelas Eksperimen

\begin{tabular}{|c|c|c|c|}
\hline No & $\begin{array}{c}\text { Rentang } \\
\text { Nilai }\end{array}$ & Kategori & $\begin{array}{c}\text { Jumlah } \\
\text { Mahasiswa } \\
\text { PBSI } \\
\text { UMUS } \\
\end{array}$ \\
\hline 1. & $85-100$ & $\begin{array}{c}\text { Sangat } \\
\text { Baik }\end{array}$ & 9 \\
\hline 2. & $75-84$ & Baik & 21 \\
\hline 3. & $65-74$ & Cukup & - \\
\hline 4. & $00-64$ & Kurang & - \\
\hline \multicolumn{3}{|c|}{ Jumlah } & 30 \\
\hline
\end{tabular}

Berdasarkan pada tabel 1 dapat dikemukakan bahwa hasil tes awal atau pretes yang dilaksanakan sebelum mendapatkan perlakuan (treatment) yaitu skor terendah 64 dan skor tertinggi 84. Dari data tersebut terlihat bahwa ada 25 mahasiswa yang belum tuntas. Hal tersebut dibuktikan dengan pencapaian nilai materi dakwah antar rentang $75-84$ sebanyak 5 mahasiswa, 65-74 sebanyak 16 mahasiswa dan 00-64 sebanyak 9 mahasiswa.
Selanjutnya, data nilai materi dakwah pada tes akhir (posttest) kelas eksperimen diberi perlakuan dengan media vlog. Proses media vlog tersebut dapat dilihat pada gambar berikut.

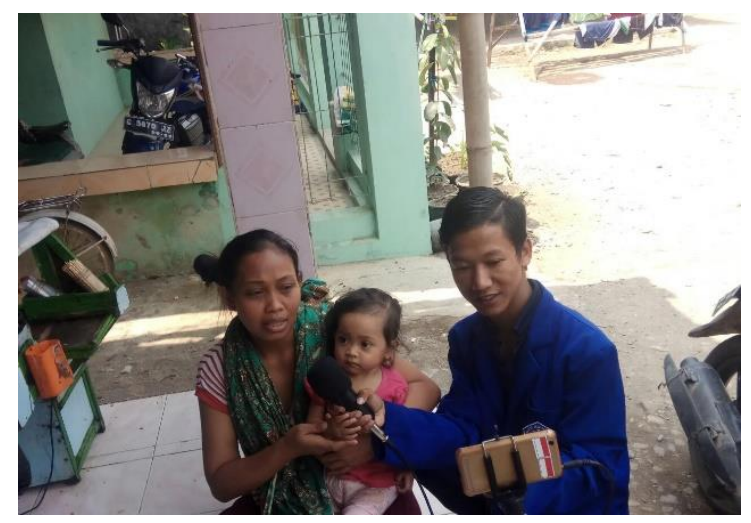

Setelah mahasiswa mendapat perlakuan dengan menggunakan media vlog pada materi dakwah maka diperoleh nilai akhir (posttest). Nilai akhir tersebut dapat dilihat pada Tabel 2 berikut ini.

Tabel 2. Nilai Akhir (posttest) Kelas

\begin{tabular}{cccc}
\hline No & $\begin{array}{c}\text { Rentang } \\
\text { Nilai }\end{array}$ & Kategori & $\begin{array}{c}\text { Jumlah } \\
\text { Mahasiswa } \\
\text { PGSD } \\
\text { UMUS }\end{array}$ \\
\hline 1. & $85-100$ & $\begin{array}{c}\text { Sangat } \\
\text { Baik }\end{array}$ & - \\
2. & $75-84$ & Baik & 5 \\
3. & $65-74$ & Cukup & 16 \\
4. & $00-64$ & Kurang & 9 \\
\hline \multicolumn{2}{c}{ Jumlah } & & 30 \\
\hline
\end{tabular}

Eksperimen

Berdasarkan pada tabel 2 dapat dikemukakan bahwa hasil tes akhir (posttest) materi dakwah dilaksanakan dengan menggunakan media vlog yaitu skor terendah 75 dan skor tertinggi 89 . Dapat dikatakan bahwa hasil tes akhir mahasiswa sudah tuntas semua. Hal tersebut dibuktikan dengan pencapaian nilai kemampuan menulis teks prosedur antar rentang $75-84$ sebanyak 21 mahasiswa dan 85 - 100 sebanyak 9 mahasiswa. 


\section{b. Keefektifan Media Vlog}

Keefektifan media vlog materi dakwah terdiri atas uji normalitas data, uji homogenitas data, dan uji hipotesis data. Uji normalitas data dapat dilihat pada Tabel 3 berikut ini.

Tabel 3. Uji Normalitas Data

\section{Tests of Normality}

Shapiro-Wilk

\begin{tabular}{llll}
\hline & Statistic & Df & Sig. \\
\hline Nilai & .923 & 60 & .054 \\
\hline
\end{tabular}

Berdasarkan tabel 3, Uji normalitas yang digunakan menggunakan ShapiroWilk, yang diperoleh signifikansi sebesar 0,054 lebih besar dari 0,05 (signifikansi yang digunakan), maka ha ditolak dan ho diterima, artinya data tersebut berdistribusi normal.

Setelah dilakukam uji normalitas data, selanjutnya yaitu uji homogenitas data. Untuk lebih lengkapnya dapat dilihat pada Tabel 4 berikut ini.

Tabel 4. Uji Homogenitas Data Test of Homogeneity of Variances Nilai

\begin{tabular}{llll}
\hline Levene Statistic & df1 & df2 & Sig. \\
.124 & 1 & 50 & .153 \\
\hline
\end{tabular}

Berdasarkan tabel 4 tersebut dapat disimpulkan bahwa nilai signifikansi yaitu 0,153 lebih besar dari 0,05 (signigfikansi yang digunakan). Oleh karena itu maka ha ditolak dan ho diterima. Dengan demikian dapat disimpulkan bahwa nilai pretest dan posttest dapat dikatakan homogen.

Setelah melalui uji syarat yaitu uji normalitas data dan uji homogenitas data, selanjutnya dilakukan uji hipotesis data dengan mengggunakan Independent Sample Test. Berikut hasil perhitungannya dilihat pada tabel 5 .
Tabel 5. Independent Samples Test

\begin{tabular}{|c|c|c|c|c|c|}
\hline & \multirow{2}{*}{\multicolumn{2}{|c|}{$\begin{array}{l}\text { Levene's } \\
\text { Test for } \\
\text { Equality of } \\
\text { Variances }\end{array}$}} & \multicolumn{3}{|c|}{ t-test for Equality of Means } \\
\hline & & & & & \\
\hline & $\mathrm{F}$ & Sig. & $\mathrm{T}$ & Df & $\begin{array}{l}\text { Sig. (2- } \\
\text { tailed) }\end{array}$ \\
\hline $\begin{array}{c}\text { Nilai Equal } \\
\text { variances } \\
\text { assumed }\end{array}$ & .173 & .153 & 3,577 & 60 & .000 \\
\hline $\begin{array}{l}\text { Nilai Equal } \\
\text { variances } \\
\text { not } \\
\text { assumed }\end{array}$ & & & 3,577 & 47.024 & .000 \\
\hline
\end{tabular}

Berdasarkan tabel 5 tersebut terlihat bahwa t hitung $=3,577$ sedangkan $t$ tabel $=2,00$. Artinya $t$ hitung $>\mathrm{t}$ tabel. Hal ini berarti $H_{0}$ diterima. Jadi, ada pengaruh antara variabel bebas dengan tingkat kepercayaan $95 \%$ atau $\alpha=5 \%$ dengan (df) $=60$. Oleh karena itu dapat disimpulkan bahwa terdapat perbedaan yang signifikan antara rata-rata nilai mahasiswa pretes dan postes kelas eksperimen dengan media vlog. Dapat dikatakan bahwa media vlog meningkatkan kemampuan mahasiswa dalam berdakwah khususnya keterampilan berbahasa (berbicara).

Media vlog merupakan media yang sejalan dengan perkembangan era sekarang. Oleh karena itu, seorang pendidik harus kreatif dan inovatif dalam pengembangan media. Hal tersebut dilakukan agar lebih kmudah tercapainya pembelajaran. Selain itu, pembelajaran juga akan lebih menyenangkan. [10]

\section{SIMPULAN}

Pada mata kuliah PAI materi dakwah untuk mahasiswa PGSD menggunakan media vlog. Berdasarkan data nilai awal (Pretest) bahwa banyak mahasiswa yang belum tuntas. Namun setelah diberi perlakuan dan diberi tes akhir (Pretest), semua mahasiswa bisa tuntas dalam materi dakwah. 
Jurnal KONTEKSTUAL, Volume 1, No. 01, Agustus 20XX, pp. 18-25

Uji keefektifan dilakukan dengan beberapa uji yaitu uji normalitas data, uji homogenitas, dan uji hipotesis. Berdasarkan tabel pengolahan data menggunakan SPSS dapat diketahui bahwa data nilai awal (pretest) dan data nilai akhir (posttest) berdistribusi normal dan homogen. Setelah dilakukan uji syarat (uji normalitas data dan homogenitas data) tahap selanjutnya yaitu uji hipotesis. Uji hipotesis menggunakan independent samples test dalam SPSS. Berdasarkan hasil uji yang dilakukan menyatakan bahwa adanya perbedaan signifikan hasil pretest dan posttest pada mahasiswa Pendidikan Guru Sekolah Dasar UMUS. Nilai t hitung lebih besar dari nilai t tabel. Sehingga dapat disimpulkan bahwa media vlog dapata diterapkan dalam materi dakwah.

Saran untuk dosen di Universitas maupun perguruan tinggi lain bahwa pemanfaatan media pembelajaran sangat berpengaruh signifikan terhadap hasil pebelajaran. Dalam hal ini yaitu materi dakwah. Pemanfaatan media berbasis IT yaitu vlog sangat berpengaruh untuk materi dakwah. Selain itu, media vlog ini sudah sejalan dengan perkembangan era sekarang yaitu menuntut dalam segala bidang untuk menggunakan teknologi informasi.

\section{REFERENCES}

[1] Sumadi, Eko, 2016, Dakwah Dan Media Sosial: Menebar Kebaikan Tanpa Diskrimasi, At-Tabsyir: Jurna komunikasi penyiaran Islam, No. 1, Vol. 4, [Online]. Available: http://journal.stainkudus.ac.id/inde x.php/komunikasi/article/download $\angle 2912 / 2083$

[2] Priana, Ronny Yudhi Septa, 2017, Pemanfaatan Vlog Sebagai Media Pembelajaran Teritegrasi Tekhnologi Informasi, Prosiding Seminar Nasional Pendidikan FKIP UNTIRTA 2017
[3] Musthofa, 2016, Prinsip Dakwah via Media Sosial, APLIKASIA: Jurnal Aplikasi Ilmu-ilmu Agama, No.1, Vol. 16, [Online]. Available: http://ejournal.uinsuka.ac.id/pusat/aplikasia/article/do wnload/1175/1068

[4] Jamalie, Zulfa, 2015, Pola Dakwah Pada 'Masyarakat Suku Terasing' Di Kalimantan Selatan, Jurnal Dakwah, No.1, Vol. XVI, [Online]. Available: https://media.neliti.com/media/publi cations/77404-ID-pola-dakwahpada-masyarakat-suku-terasin.pdf

[5] Sadly, Effendi, 2018, Manajemen Dakwah Media Sosial: Telaah Terhadap Perkembangan Metode Dakwah Islam. jurnal Riset Manajemen \& Bisnis (JRMB). No. 2, Vol. 3,_[Online]. Available: https://jurnal.uisu.ac.id/index.php/J RMB/article/download/902/778

[6] David, Eribka Ruthellia dkk, 2017, Pengaruh Konten Vlog dalam Youtube terhadap Pembentukan Sikap Mahasiswa Ilmu Komunikasi Fakultas Ilmu Sosial dan Politik Universitas Sam Ratulangi, e-journal "Acta Diurna" No. 1, Vol. VI, [Online]. Available:

https://media.neliti.com/media/publi cations/93363-ID-pengaruh-kontenvlog-dalam-youtube-terha.pdf

[7] Indayatmi, 2018, Pengaruh Vlog Pembelajaran Terhadap Peningkatan Hasil Belajar Peserta Didik Smk Negeri 2 Depok, Jurnal Pendidikan Sains, No. 1, Vol. 06,_[Online]. Available: https://jurnal.unimus.ac.id/index.php /JPKIMIA/article/view/3296/pdf 
Jurnal KONTEKSTUAL, Volume 1, No. 01, Agustus 20XX, pp. 18-25

[8] Cahyani, Novianti Ayu, 2017, Penerapan Metode Vaks (Visual, Auditory. Kinestethic, Sugestopedia) Untuk Meningkatkan Ketrampilan Berbicara Pada Materi Memerankan Tokh Drama, Jurnal Pena Ilmiah, Vol. 2, No.1, [Online]. Available:

http://ejournal.upi.edu/index.php/p enailmiah/article/download/10470/ $\underline{6465}$

[9] Sugiyono, 2012, Metode Penelitian Kuantitatif Kualitatif $R \& D$. Bandung: Alfabeta

[10] Nurpratiwiningsih, Laelia, 2018, Development of Education Games Map Material as a Learning Media for Elementary School Students, Journal of Primary Education, No. 7, Vol. III, [Online]. Available: https://journal.unnes.ac.id/sju/index. php/jpe/article/view/26251 